\title{
Relevancy, Probability and the Law
}

\author{
George F. James*
}

SINCE scholars first attempted to treat the common law of evidence as a rational system, relevancy has been recognized as a basic concept underlying all further discussion. Thayer gave this recognition its classic form:

"There is a principle-not so much a rule of evidence as a presupposition involved in the very conception of a rational system of evidence, as contrasted with the old fornal and mechanical systems -which forbids receiving anything irrelevant, not logically probative."1

"The two leading principles should be brought into conspicuous relief, (1) that nothing is to be received which is not logically probative of some matter requiring to be proved; and (2) that everything which is thus probative should come in, unless a clear ground of policy or law excludes it."2

The proposed Code of Evidence of the American Law Institute (hereinafter referred to as the Code) substantially follows Thayer. ${ }^{3}$

Early attempts to state the requirements of relevancy were confused and fragmentary, but in the suggested rules, and even more in the suggestive illustrations, the germ of modern doctrine-both sound and fallacious-may be found. Thus Phillipps, writing in 1814, stated five primary general rules governing the testimony of witnesses, of which the first was that "Evidence must be confined to the points in issue". "The author then expanded and illustrated this general rule, saying in part

"And, first, as the intent of evidence is to ascertain the truth of the several disputed facts or points in issue, either on one side or the other, no evidence ought to be admitted to any other point. Thus,

*Associate Professor of Law and Assistant Dean, University of Chicago Law School; Ph.B., J.D., University of Chicago; LL.M., Columbia University. Author of articles in various legal periodicals.

1 Thayer, A Prethotinary Treattse on Evmeance at the Comocon law (1898) 264.

2 Ibid. at 530.

3 "'Relevant evidence' means evidence having probative value upon any material matter and includes opinion evidence and hearsay evidence." " Material matter' means a nuatter the existence or non-existence of which is provable in the action." "...all relevant evidence is admissable." CODE OR Evmence T. No. 2 (Am. L. Inst. 1941) Rules $1(10), 1(7), 9(f)$.

4 PenIIPPS, EvHonce (1814) 69. 
for example, in an action of debt upon a bond, if the defendant pleads non est factum, (which puts in issue whether it be the defendant's deed or not), he cannot give a release in evidence. Nor, in an action of trespass for an assault and battery, will the defendant be allowed to prove, under the general issue, that he was first assaulted by the plaintiff. For the same reason, it would not be allowable to shew, on the trial of an indictment, that the prisoner has a general disposition to commit the same kind of offence as that charged against him. Thus, in a prosecution for an infamous crine, an admission by the prisoner that he had counmitted such an offence at another time and with another person, and that he had a tendency to such practices, ought not to be admitted. So, when a right is claimed by custom in a parish, proof of a similar usage in an adjoiming parish, is not evidence of the custom. But where all the manors within a certain district are held by the same peculiar tenure, and a question arises, in any one of the manors, upon an incident to the tenure, evidence may be given of the usage which prevails in any of the other manors within the district."

Phillipps' illustrations bring out a double meaning in the requirement of relevancy which continues in the modern statements and tends to produce confusion in the cases. Relevancy, as the word itself indicates, is not an inherent characteristic of any itenı of evidence but exists as a relation between an item of evidence and a proposition sought to be proved. If an item of evidence tends to prove or to disprove any proposition, it is relevant to that proposition. If the proposition itself is one provable in the case at bar, or if it in turn forms a further link in a chain of proof the final proposition of which is provable in the case at bar, then the offered item of evidence has probative value in the case. Whether the immediate or ultimate proposition sought to be proved is provable in the case at bar is determined by the pleadings, by the procedural rules applicable thereto, and by the substantive law governing the case. Whether the offered item of evidence tends to prove the proposition at which it is ultimately aimed depends upon other factors, shortly to be considered. But because relevancy, as used by Thayer and in the Code, means tendency to prove a proposition properly provable in the case, an offered item of

5 Ibid. Peake, on whose text Phillipps greatly relied, had said in 1801, "Another rule is, that the evidence must be applied to the particular fact in dispute; and therefore no evidence not relating to the issue, or in some manner connected with it, can be received; nor can the character of either party to a civil cause be called in question, unless put in issue by the very proceeding itself, for every cause is to be decided on its own circumstances, and not to be prejudiced by any matter foreign to it." PEAKE, A CoMpendiuM of the Law of Evidence (4th ed. 1813) 7. 
evidence may be excluded as "irrelevant" for either of these two quite distinct reasons: because it is not probative of the proposition at which it is directed, or because that proposition is not provable in the case. ${ }^{0}$

The distinction between these two senses of irrelevance seems not to have been observed by the early authors. Thus Phillips combines in a smgle paragraph a rule against evidence of a release under a plea of non est factum with a rule against proving the custoins of one parish by evidence of the customs in an adjoining one, and even states that rules against proof of self defense under the general issue in an assault and against showing the general criminal disposition of an accused exist "for the same reason".

Only lack of careful analysis-an easy satisfaction with surface similarities-can explain such statements as Phillipps'. A little consideration shows that in the bond case, for example, no one would suppose or urge that proof of a release is in any sense probative of the proposition that the defendant never executed the bond sued upon. This evidence must have been offered in the erroneous belief that it constituted an ultimate material fact available as a defense. On the other hand, it is equally clear that proof or disproof of the custom of parish $B$ would not be material-in the sense of involving an ultimate material fact-im a suit brought or defended on the custom of parish $A$. In such a case the custom in $B$ could be useful only if relevant, as giving the basis for a permissible inference as to the custom in $A$. Phillipps' appreciation of the form of the argument in the second case, together with a basic understanding of the "methods of agreement and difference", 7 appears from his approval of a third case, ruling that usage in one manor may be proved to show the mcidents of tenure in another manor in the district provided the two are held by the same peculiar tenure. Nevertheless, he places these three cases together without noting that in the first we are dealing with a problem of pleading, while genuine questions of evidence arise in the second and third.

The same confusion can exist between questions of evidence and

6 Henceforth, for brevity, propositions of ultimate fact properly provable in a case under the pleadings and substantive law will be referred to as "material propositions"; the characterization "relevant" will be reserved for propositions of evidence which, whether or not material themselves, tend to prove other propositions which are material. "Irrelevant" and "immaterial" are of course the contraries of the two first terms, as defined.

7 See 1 WigMore, EvmEarcs (3d ed. 1940) § 12. 
of substantive law, as Phillipps proceeds to demonstrate by according uniform and consolidated treatment to cases holding that a civil defendant cannot prove his good character, even to rebut imputations of fraud, that in an action for criminal conversation the defendant unay prove the light character of the plaintiff's wife (in mitigation of damages), and that in an action for malicious prosecution the defendant, after circumstances of suspicion, may show the plaintiff's generally bad character as evidence of reasonable suspicion.

Under modern codes the substantive law confusion is more comunon than the one based on rules of pleading, and may appear in very subtle forms. Let us analyze a single interesting case, Union Paint \&. Varnish Co. v. Dean, ${ }^{8}$ an action of assumpsit to recover the purchase price of waterproof roof paint. The defendant relied upon the plaintiff's warranty that the pamt would wear for ten years, breach of which he sought to show by proof that another drum of paint of the same brand, which he had purchased six months earlier, not only had failed to prevent leaks but had ruined the shingles to which it had been applied. The drum of paint in issue, purchased just before leaks developed in the first roof painted, had never been opened. Reversing the trial court, the Supreme Court of Rhode Island held that the defendant's offer of proof (apparently almost the only evidence offered in defense) should have been received, saying:

"If paint of the same brand, sold by the same concern under the same warranty within six months, had proved within that time to be not in conformity with the warranty, in that it was not only not suitable for stopping and preventing leaks but was actually injurious to a roof, a person might well hesitate before using more paint of the same brand when he had no reason to expect the second lot to be any better than the first."

Considered as evidence of the condition of the second drum of paint, proof of the results of use of the first is not very impressive. Waiving any doubts whether the leaks in the first roof were traceable to defects in paint in the first drum, there is no showing whether the defects in the first drum of paint were due to poor ingredients, to a poor formula, or to some error in preparation. If poor ingredients had been used, there is no showing that use of poor ingredients was a policy of, rather than an error of, the plaintiff company. It is easier to believe that one lot of defective paint went out than it is to believe

8 (1927) 48 R. I. 288, 137 Atl. 469; Morgan and Magutre, CASES on Evidence (1937 reprint) 289.

B Ibid. at 291, 137 Atl. at 470. 
that plaintiff customarily sold, under a ten-year guaranty, waterproof roof paint which would rot out shingles and cause leaks in six months. And the two drums of paint were probably not out of one lot; certainly there was no showing that they were. Proof of the condition of the paint in the first drum was of negligible value in judging the probable character of the paint in the second, unopened drum. It merely showed that plaintiff company sometimes sold bad paint. If the issue was whether the paint in the second drum was bad, an issue on which the defendant had the burden, the trial judge's ruling seems sound. At worst, the issue is close enough so that an appellate court should not reverse. Yet there is still a ring of reason to the supreme court's statement that "a person might well hesitate before using more paint of the same brand". He would hesitate to risk ruiming a second roof even if he only feared that the second drum of paint might be no better than the first. And if he was reasonable in his hesitation, should the plaintiff be allowed to recover even if it could show at trial that the paint in the second drum was perfectly good? The defendant, reasonably hesitant to use the doubtful paint, by now has probably painted all of his roofs with some other paint and has no further use for the drum which he is tendermg back to the vendor. If the customer is to be protected, even against proof that the second drum of paint was in fact satisfactory (as the writer should like to do in such a case ${ }^{10}$ ), a novel rule of substantive law stands revealed behind a somewhat doubtful ruling on evidence.

But after excluding all cases which turn upon the materiality or immateriality under the pleadings and substantive law of ultimate propositions sought to be proved, there remain many cases in which there is no question of the materiality of the proposition sought to be proved and the probative value of the offered evidence is the real issue. These cases, and these alone, raise the problem of relevancy as a problem in the law of evidence. How should they be handled?

Thayer, after stating the principle which forbids receiving anything not "logically probative", excluded legal criteria from further operation, saying

"How are we to know what these forbidden things are? Not by any rule of law. The law furnishes no test of relevancy. For this, it tacitly refers to logic and general experience,-assuming that the

10 Professor Malcolm Sharp, my colleague who deals with contracts, expressed his offhand opinion that the bad quality of the paint in the first drum should serve the buyer as an excuse for non-acceptance of a second drum of the "same paint"-i.e., paint sold under the same brand. 
principles of reasoning are known to its judges and ministers, just as a vast multitude of other things are assumed as already sufficiently known to them."11

Wigmore, agreeing with Thayer in much, questions the conclusion that the law furnishes no test of relevancy, ${ }^{12}$ citing in opposition a well-known passage by Chief Justice Cushing of New Hampshire:

"... although undoubtedly the relevancy of testimony is originally a matter of logic and common sense, still there are many instances in which the evidence of particular facts as bearmg on particular issues has been so often the subject of discussion in courts of law, and so often ruled upon, that the united logic of a great many judges and lawyers may be said to furnish evidence of the sense common to a great many imdividuals, and, therefore, the best evidence of what nay be properly called common-sense, and thus to acquire the authority of law. It is for this reason that the subject of the relevancy of testimony has become, to so great an extent, matter of precedent and authority, and that we may with entire propriety speak of its legal relevancy." 13

This question of the propriety of speaking of "legal relevancy", of the expediency of framing rules with the authority of law to govern offers of evidence of particular facts as bearing on particular issues, is the central one in circunsstantial proof. But since it is agreed on all sides that relevancy is at least originally a matter of logic and common sense rather than a matter of law, let us first see whither logic and common sense lead us, and by what means.

Dean Wigmore, recognizing this priority of logic, discusses the form of argument involved in the use of circumstantial evidence. His views deserve extended quotation and criticism. After stating that proof reduces to two great forms, inductive and deductive, and quoting Professor Sidgwick's description of the two, Wigmore states:

"A brief examination will show that in the offering of evidence in Court the form of argument is always inductive. Suppose, to prove a charge of nurder, evidence is offered of the defendant's fixed design to kill the deceased. The form of the argument is: 'A planned to kill $\mathrm{B}$; therefore, A probably did kill $\mathrm{B}$.' It is clear that we have here no semblance of a syllogism. The form of argument is exactly the same when we argue: 'Yesterday, Dec. 31, A slipped on the sidewalk and fell; therefore, the sidewalk was probably coated with ice'; or, 'To-

11 TrRAYER, op. cit. supra note 1 , at 265.

121 WIGMORE, loc. cit. supra note 7.

13 State v. LaPage (1876) 57 N. H. 245, 288. Wigmore suggests that the difference between Thayer and Cushing is "one of nomenclature only", a very fundamental error as should appear hereinafter. 
day A, who was bitten by a dog yesterday, died in convulsions; therefore, the dog probably had hydrophobia.' So with all other legal evidentiary facts. We may argue: 'Last week the witness A had a quarrel with the defendant $B$; therefore, $A$ is probably biassed against $B$ '; 'A was found with a bloody knife in B's house; therefore, A is probably the murderer of B'; After B's injury at A's machinery, A repaired the machinery; therefore, $A$ probably acknowledged that the machinery was neghigently defective'; ' $A$, an adult of sound mind and senses, and apparently impartial, was present at an affray between B and C, and testifies that B struck first; therefore, it is probably true that $B$ did strike first.' In all these cases, we take a single or isolated fact, and upon it base immediately an inference as to the proposition in question.

"It may be rephed, however, that in all the above instances, the argument is implicitly based upon an understood law or generalization, and is thus capable of being expressed in the deductive or syllogistic form. Thus, in the first instance above, is not the true form: 'Men's fixed designs are probably carried out; A had a fixed design to kill $B$; therefore, A probably carried out his design and did kill B'?

"There are two answers to this. (1) It has just been seen that every inductive argument is at least capable of being transunuted into and stated in the deductive form, by forcing into prominence the implied law or generalization on which it rests nnore or less obscurely. Thus it is nothing peculiar to litigious argnment that this possibility of turning it into deductive form exists here also. It is not a question of what the form might be-for all inductive may be turned into deductive forms-, but of what it is, as actually employed; and it is actually put forward in inductive form. (2) Even supposmg this transmutation to be a possibility, it would still be undesirable to make the transmutation for the purpose of testing probative value; because it would be useless. We should ultimately conne to the same situation as before. Thus, in one of the instances above: 'A repaired machinery after the accident; therefore, $A$ was conscious of a negligent defect in it'; suppose we turn this into deductive form: 'People who make such repairs show a consciousness of negligence; A made such repairs; therefore, A was conscious of neghigence.' We now have an argument perfectly sound deductively, i.e. if the premises be conceded. But it remains for the Court to declare whether it accepts the major premise, and so the Court must now take it up for examination, and the proponent of the evidence appears as its champion and his argument becomes: 'The fact that people make such repairs indicates (shows, proves, probably shows, etc.) that they are conscious of neghigence.' But here we come again, after all, to an inductive form of argument. The consciousness of neghigence is to be inferred from the fact of repairs,-just as the presence of electricity in the clouds was inferred by Franklin from the shock through the kite-string, i.e. by a purely inductive form of reasoning. So with all other evi- 
dence when resolved into the deductive form; the transmutation is useless, because the Court's attention is merely transferred from the syllogism as a whole to the validity of the inference contained in the major premise; which presents itself again in inductive form.

"For practical purposes, then, it is sufficient to treat the use of litigious evidentiary facts as inductive in form." 14

Note, Wigmore does not deny that in every instance proof must be based upon a generalization connecting the evidentiary proposition with the proposition to be proved..$^{15}$ Conceding this, he argues that the generalization may as well be tacitly understood as expressed, that "the transmutation [from the inductive to the deductive form] is useless, because the Court's attention is merely transferred from the syllogism as a whole to the validity of the inference contained in the major premise". ${ }^{16}$ Yet it is precisely in this transfer of attention that the value of the transmutation lies. The author's own exanples illustrate the point. In the case of the repaired machinery we are told: "People who make such repairs [after an accident] show a consciousness of negligence; A made such repairs; therefore, $A$ was conscious of neglience." "17 Before this deductive proof can be evalu-

141 WIGMORE, op. cit. supra note 7, at 416 . Compare Starkie's equally surprising observation: "Circumstantial, or, as it is frequently termed, presumptive evidence, is any which is not direct and positive.

"An inference or conclusion from circumstantial or presumptive evidence may be either the pure result of previous experience of the ordinary or necessary connection between the known or admitted facts, and the fact inferred, or of reason exercised upon the facts, or of both reason and experience conjointly. And hence such an inference or conclusion differs from a presumption, although the latter term has sometimes, yet not with strict propriety, been used in the same extended sense. For a presumption in strictness is an inference as to the existence of one fact, from a knowledge of the existence of some other fact, made solely by virtue of previous experience of the ordinary connection between the known and inferred facts, and independently of any process of reason in the particular instance." STARKIE, EvIDENCE *478.

15 The argument thus far may be summarized as follows: Relevancy is formal relation between two propositions. To determine the relevancy of an offered item of evidence one must first discover to what proposition it is supposed to be relevant. This requires analysis of the express or tacit argument of counsel. Then, since evidence is admissible only if relevant to a material proposition, analysis of the pleadings and applicable substantive law is required to determine whether the proposition ultimately sought to be proved is material. Having isolated the material proposition sought to be proved, we still must determine whether the evidentiary proposition is relevant to it-does tend to prove it. This tendency to prove can be demonstrated only in terms of some general proposition, based most often on the practical experience of the judge and jurors as men, sometimes upon generalizations of science introduced into the trial to act as connecting links. If the evidentiary proposition itself is material, there is no problem of relevancy.

161 WIGMORE, op. cit. supra note 7 , at 417 .

17 Ibid. 
ated, ambiguity must be eliminated from the major premise. By "people" shall we understand "some people" or "all people"? If the argument is intended to read, "Some people who make sucl repairs show consciousness of neglience; $A$ made such repairs; therefore, $A$ was conscious of negligence," it contains an obvious logical fallacy. If intended to read, "All people who make such repairs show consciousness of negligence; $A$ made such repairs; therefore, $A$ was conscious of negligence," it is logically valid. However, few could be found to accept the premise that all persons who repair machinery after an accident show consciousness of guilt; that is, that no single case could be found of one who, confident of his care in the past, nevertheless made repairs to guard against repetition of an unforeseeable casualty or to preserve future fools agaimst the consequence of their future folly. Here the result of transmuting a proposed direct inference into deductive form is discovery that it is invalid-at least in the terms suggested.

The other proposed argument is equally interesting: "Men's fixed desigus are probably carried out; $\mathrm{A}$ had a fixed design to kill $\mathrm{B}$; therefore, A probably did kill B.'" 18 Once one attempts to deal, in a quasi-syllogistic form, not with certainties but with probabilities, additional opportunities for fallacy are presented. Suppose that it is argued: "Most $A$ s are $X, B$ is an $A$, therefore $B$ is probably $X$ "; or "Nine-tenths of all $A \mathrm{~s}$ are $X, B$ is an $A$, therefore the chances are nine to one that $B$ is $X$." Neither of these arguments is logically valid except upon the assumption that $A$ s may be treated as a uniform class with respect to the probability of their being $X$. This can be because there really is no way of sub-dividing the class, finding more $X \mathrm{~s}$ in one sub-class than in another, or because no subdivision can be made in terms of available data. Suppose that nine-tenths of all people in the world have dark eyes. If absolutely all one knew about $B$ was that he was a person, it would be an apparent nine-to-one chance that $B$ had dark eyes. But if one knew $B$ to be a Swede, the percentage of dark eyes in the total population of the world would no longer be important. One would want to know about the proportion of darkeyed Swedes, which might differ from the ratio among humans generally. ${ }^{10}$ Similarly in Wigmore's example. We know that we are inter-

18 Ibid.

19 The form of the invalid argument would be as follows: Nine-tenths of men have dark eyes. $B$ is a Swede. All Swedes are men. Therefore nine chances to one $B$ has dark cyes. 
ested in the probability of execution of a fixed design of a particular kind: to commit nurder. There may be variation in the probability of execution of fixed designs on various subjects. As an initial criticisin, therefore, the primary generalization should be "Men's fixed designs to kill are probably carried out." In this form we have a valid, quasi-syllogistic argument based upon the limited data available. ${ }^{20}$ Still, is the premise sound?

"Men's fixed designs to kill are probably carried out," as a major premise in this argument, must mean that they are carried out more often than not. While the word "probable" can be used in other senses, its meaning here is clear. Hence one would conclude from the simgle datum that $A$ had a fixed design to kill $B$, no other evidence being offered, that more likely than not $A$ actually did kill $B$. But when this argument was presented to a group of law students and teachers, only one was willing to accept the indicated conclusion. Several would accept it if supported by adequate evidence that $B$ had been intentionally killed by some one. Others refused to accept it without still further evidence connecting $A$ with $B$ 's death, or at the very least evidence that $B$ had no other enemies. Moreover, there was less hesitancy in accepting the argnment in its "inductive" form. Once the generalization was made explicit, and particularly after discussion of the meaning of "probably" as there used, doubts as to the propriety of the inference arose or sharpened. The demonstration, however "valid", is no better than its major premise, and the more one considers this premise the less reliable it looks. Certainly a permitted inference shonld rest upon some more easily acceptable law.

Of course, it does not follow that a proposed inference is improper because it can be shown not to follow on the basis of one possible generalization, or because another-which by the rules of logic would validate the inference-is unacceptable. There may be a third law, as yet unexpressed, which wonld justify the inference and at the same time be commonly accepted as true. And it may be very important to find the valid and accurate link, since the form of the link will control the form of the conclusion.

Persons who are unwilling to agree that men's fixed designs (at least in case of inurder) are "probably" carried out-or, even con-

20 Probability is not an actual state. Nothing really is probable. It is true or false. Probability is a matter of appearance. Apparently probability is always relative to the data available at the time judgment is exercised. If all possible data were available we should be dealing not with probability in an ordinary sense but with the approximation of certainty. 
ceding the fact of murder, that proof of $A$ 's fixed design to kill $B$ establishes $A$, more likely than not, as $B$ 's killer-still agree that somehow this bit of evidence does have some tendency to imdicate $A$ 's guilt. What form of general statement can reconcile these views? Perhaps something like this: "Men having such a fixed design are more likely to kill than are men not having such a fixed design." Those who contend that even fixed designs to kill are more often abandoned or thwarted than carried out can and doubtless will still concede that enough such desigus are carried to execution so that the percentage of murderers is higher among persons entertaining such a fixed design than among the general public. Obviously this proposed generalization does not lead us from $A$ 's fixed design to kill $B$ to the conclusion that $A$ probably did kill $B$. There is nothing disturbing im this. This conclusion simply does not follow from the evidence of design. The error was in the original "direct induction". In fact, no useful conclusion about $A$ 's guilt can be drawn from desigu or intent alone. On the basis of an acceptable generalization we are able only to place $A$ in a class of persons in which the incidence of murder is greater than among the general public. We cannot now say that $A$ is probably gnilty, but we can say that the apparent probability of his guilt is now greater than before the evidence of design was received. ${ }^{21}$ This is logical relevancy-the only logical relevancy we can expect in dealing with practical affairs where strict demonstration is never possible. ${ }^{22}$ The advantage of the transmutation into deductive (though not strictly syllogistic) form is that we know to what degree of proof we have attained, and do not overstate our results. ${ }^{23}$

Before leaving the subject of imduction and deduction, consider

21 Or, the apparent probability of his innocence is now less. The two statements mean the same.

22 It should be unnecessary to point out the fundamental distinction between relevancy of evidence and the degree of probability necessary to establish a prima facie case. Almost every careful writer has discussed it. See, for example, 1 WIGMore, op. cit. supra note $7, \S \S 28,29$. If the sum total of evidence received falls short of satisfying the burden of persuasion, the jury is there for the express purpose of finding against the party who must bear that burden. If the sum total of evidence received is so slight that the jury as rcasonable men could not be persuaded, the trial judge may enter a non-suit or direct a verdict. There is no reason for worrying about such issues while passing upon an offer of evidence. The one exception might be an item of evidence which, although logically relevant in a very remote sense, is so shight that in the opinion of the trial judge it could not sway an even balance.

23 In some cases we may be able to discover no acceptable generalization to connect the offered evidence to any material proposition. Such cases will be very rare, unless they involve errors of pleading or substantive law. 
one more example. Wigmore asserts: "There is just as much probative value in the argument ' $A$ is quarrelsome, therefore he probably committed this assault,' as in the argument, ' $B$ is peaceable, therefore he probably did not commit the assault ...." pear when the two arguments are stated as direct inductions. But transmutation of the two arguments shows a different result. In the second case we say: "Peaceable men are not likely to commit assaults. $B$ is a peaceable man. Therefore he was not likely to commit (this or any) assault." In the first case the most we can say is: "Quarrelsome men are more likely than others to commit assaults. $A$ is quarrelsome. Therefore he is more likely than others to commit assaults." This may be equally good if there is no doubt of an affray between $A$ and $B$, one of them surely being the aggressor. But suppose that we know someone assaulted $C$ and are attempting to decide whether $A$ or $B$ or some third person was the culprit. We know that $B$, the peaceable man, was unlikely to commit any assault, hence unlikely to have committed the one in issue. All we know of $A$, the quarrelsome fellow, is that he has a general predilection for trouble. While it is some help, it does not show an affirmative probability of his guilt in any particular case. There is a definite difference in the probative value of the two offers of proof.

Nevertheless, both offers of proof are logically relevant; the apparent probability of guilt in each case would be changed, though not in the same degree, by the evidence of character. Why then is the evidence rejected in the weaker case? A possible answer would be simply because it is weaker-too weak. Although logically relevant, it falls short of the minimum requirement of legal relevancy. ${ }^{25}$ Such an answer merely raises a further query. Why should there be a standard of "legal relevancy" more strict than, or in any respect different from, the standards of logic? Why exclude any data which if admitted would change the apparent probabilities and hence serve, even to a slight degree, to aid the search for truth? Justice Holmes suggested one answer, it is "a concession to the shortness of life"

241 WIGMORE, op. cit. supre note 7 , at 454.

25 Bouvier, after defining "relevancy in a logical sense" goes on to say "Legal relevancy requires a higher standard of evidentiary force. It includes logical relevancy and demands a close connection between the fact to be proved and the fact offered to prove it. The fact, however, that it is logically relevant does not insure admissibility; it must also be legally relevant." 3 BouvIER, Drctionary (Rawle's 3d ed. 1914). BLACK, LAW Dictionary (3d ed. 1933), is to the same effect.

26. Reeve v. Dennett (1887) 145 Mass. 23, 28, 11 N. E. 938, 944. 
-and perhaps to the shortness of purse of harassed litigants. If any and all evidence may be admissible which-in terms of some commonly accepted generalization about human conduct or natural events-would operate to any extent to alter the apparent probability of some material proposition, the field of judicial inquiry in most cases would be almost unlimited. Trials could come to an end only by the exhaustion of lawyers' ingenuity or clients' money, and the trial judge or jury might be overwhelmed and bewildered by the multiplicity of collateral issues. Such a rule would result in the apparent justice and the practical injustice characteristic of English Chancery practice a century and a half ago. Hence the requirement, in many cases, of something more than bare logical relevancy.

In addition to the simple factors of time, confusion and expense, other practical considerations may justify the exclusion of relevant evidence of but slight probative weight. ${ }^{2 \pi}$ As noted above, evidence is irrelevant in the clearest sense if its tendency is to prove some proposition not properly provable in the action. Sometimes the same evidence may be remotely relevant to a material proposition and directly relevant to an immaterial one; in such a case its exclusion could be justified lest the jury be misled into deciding the case on the immaterial issue. Or evidence might be excluded because under the issues as framed in the pleadings such evidence would unreasonably surprise the opponent..$^{28}$

Probably the greatest part of judicial rulings excluding evidence as irrelevant go primarily on the first principle - that the evidence is relevant, but its probative value is so shight as not to justify the time and expense involved in receiving it and the confusion of issues which might result in the mind of the trier of fact. Does this sound practical policy justify creation of the concept of "legal relevancy" -higher and more strict than logical relevancy, to which offers of proof must be referred? On the contrary, the concept can only be a nuisance. In the first place, it defies definition. ${ }^{29}$ No statement of a

$2 \pi$ All of these factors are listed as permissible grounds for the exclusion of evidence in the proposed Code, op. cit. supra note 3 , Rule 403 , which Rule is expressly made a qualification of most other rules, but is then followed by several specific and somewhat confusing rules on proof of character, habit, etc.

$28 \mathrm{~A}$ similar policy is expressed by pleading rules which require the affirmative allegation of defenses likely to surprise the opposing party, whether or not the defense is affirmative as a matter of analysis. See, e.g., IrIINors CIVIr Practice Act (1933) § 43(4).

29 See supra note 25 . Such a definition is sufficient to raise doubts in every case and to satisfy them in none. 
standard of probative value higher than logical relevancy can be made precise enough for use without excluding much evidence which is used daily, without argument and to good effect. And there is a definite reason for this. When a judge must decide whether a particular iten of evidence, logically relevant, is of sufficient force to justify the time and expense necessary to establish it, he should not confine his attention to the effect of the offered evidence alone. $\mathrm{He}$ should consider how difficult it will be to establish the evidentiary fact-whether there is any real contest about it and whether confusing side issues must be explored. He should consider how the offered evidence may fit in with other evidence. It may form a small but useful part of a.pattern of proof. It may stand alone, lending its negligible aid to unconnected lines of proof. It may be merely cumulative, so that the trouble of establishing it will result in little of practical value. He may even want to consider the importance to the parties of the issues being tried, in the light of mounting trial expense. Such considerations cannot usefully be reduced to a simple fornula for relevancy of particular items of evidence. ${ }^{30}$

The method suggested by Chief Justice Cushing, ${ }^{31}$ that of buildmg up a body of rulings on the bearing of particular facts upon particular issues, is no better-for the same reason. The ruling in each case will seldon if ever be that the offered fact has no bearing upon the issue. It will be that it has no sufficient bearing to justify its use in view of all the circumstances of the case in which it is offered. Such a precedent, rightly understood, is of no value save in another case substantially identical in all of its particulars. Treated more broadly; its tendency will be to mislead subsequent judges.

Take, as an exanple, State v. LaPage ${ }^{32}$ where Chief Justice Cushing enunciated his theories on legal relevancy. The state, in a prosecution for murder of one Josie $\mathrm{L}$. in which there was some evidence of unurder durmg an attempted rape, was permitted to show that the defendant had raped one Julienne $R$. The evidence was offered not

30 As good an attempt as any was that of Justice Cooley in Stewart v. People (1871) 23 Mich. 63, 75: "The proper test for the adinissibility of evidence ought to be, we think, whether it has a tendency to affect belief in the mind of a reasonably cautious person, who should receive and weigh it with judicial fairness." This is practically a definition of logical relevancy applied to important issues depending on indeterminate probabilities.

31 Supra note 13.

32 Ibid. 
to show that the defendant had killed Josie, but to show that if he had done so it was in the course of an attempted rape and therefore first degree murder under the New Hampshire statute. A conviction was reversed, the court holding that evidence of another crime, not relevant save as showing the character or disposition of the accused, could not be presented by the prosecution when the accused had not "put his character in issue". The reasons for this ruling are clear on principle and from the opinion itself. First, the offered evidence, while it had some probative value, was not particularly cogent. Second, by attacking the character of the accused, it raised the danger that he might be "overwhelmed by prejudice, instead of being convicted on that affirmative evidence which the law of this country requires". ${ }^{33}$ Third, by using specific instances of misconduct to demonstrate bad character, it confronted the accused with a dangerous issue which he might have been entirely unprepared to meet. These are substantial arguments for exclusion, which are in no way aided by saying that the defendant's bad character is not "legally relevant", or that specific instances of misconduct are not "legally relevant" to prove bad character.

On the contrary, there is real danger that talk of legal relevancy in such cases nay mislead other judges. Thus in a prosecution for inurder the character of the decedent as quarrelsome and violent should be admissible in aid of a plea of self-defense. Most courts admit it, ${ }^{34}$ but those who do not often seem confused by the inadmissibility of the violent character of the accused. If the ruling excluding the bad character of criminal defendants were always expressly inade on the ground that such evidence is relevant but inadmissible because unduly prejudicial, without reference to "Iegal irrelevancy", such confusion would be unlikely.

Similarly the argument of undue surprise is less likely to lead courts into error if stated as such. Specific immoral acts clearly are not irrelevant as evidence of lack of the corresponding virtue. If not actually conclusive they are certainly much more cogent than reputation. If they are really excluded because of the danger of surprise, it would be better to say so. Then courts might in time discover in pre-trial practice a method of obviating unfair surprise in the use of the specific instance whenever its value is sufficiently great to justify the time and expense of trying a collateral issue.

${ }^{33}$ Regina v. Rowton (1865) Leigh \& C. 520, 540, 169 Eng. Rep. 1497, 1506.

341 WIGMroRE, op. cit. supra note $7, \S 63$. 
Such considerations, whether taken singly or together, afford most unsuitable materials for the construction of a body of case law. Like the simpler problem of time and expense, all involve a balance of competing considerations-the value of the evidence, the importance of the point sought to be established, the availability of other evidence, the precise degree of inconvenience or prejudicenever likely to be duplicated in different cases. "The evidence of particular facts as bearing on particular issues" does not repeat its pattern closely enough to permit its petrifaction into rules having "the authority of law" without over simplification. The history of evidence has been in the development of sound principles into arbitrary and unworkable rubrics, a development not to be encouraged in case law or by code.

The remedy lies in Thayer's advice in holding to logic and general experience, assuming that the principles of reasoning are known to the judges and ministers of the law. In this analysis evidence is relevant if it can be demonstrated, in terms of some generalization acceptable to the court, to alter the apparent probability of any material proposition in the case. The generalization may rest either upon the general experience of the court or upon expert testimony, but it should be susceptible of expression.

Because of the wide range of relevant evidence under such a test, the trial judge must have discretion to exclude it, and may well be furnished with general criteria to aid, but not to control, the exercise of this discretion. Although it is rather brief, Rule 403 of the proposed Code is a step in this direction. Attempts at further specification, either by code or by decision, should then be discouraged. Limiting the review of trial court rulings on circumstantial proof will do inuch to check the proliferation of precedent. Virtually never would an appellate court be justified in reversing a trial judge for the admission of remote but non-prejudicial evidence. Time thus wasted cannot be recovered by requiring a second trial. Where remote evidence was excluded, an upper court should refuse to reverse unless it appears that a contrary ruling would actually have altered the result. To the extent that this rule allows somewhat more control than the one on erroneous admission, its tendency would be to liberalize rulings on evidence where the only objection is remoteness.

Fimally no judgment should be reversed because evidence was prejudicial, or caught the opponent by surprise, unless the objection was made on this express ground. If problems of surprise or preju- 
dice were necessarily designated as such and not lumped under the heading of irrelevancy, the bench and bar might learn, instead of regarding them primarily as ammunition of appeal, to handle them at the trial stage by instructions to the jury, by continuances, and above all by discussion of the problems of proof at pre-trial conferences. The domination of the appellate court, the printed report and the misleading precedent might be ended, the largely unrelated principles making up the concept of "legal relevancy" be disentangled, and that ambiguous phrase returned to the grave wherem the great Professor Thayer laid it almost fifty years ago. 